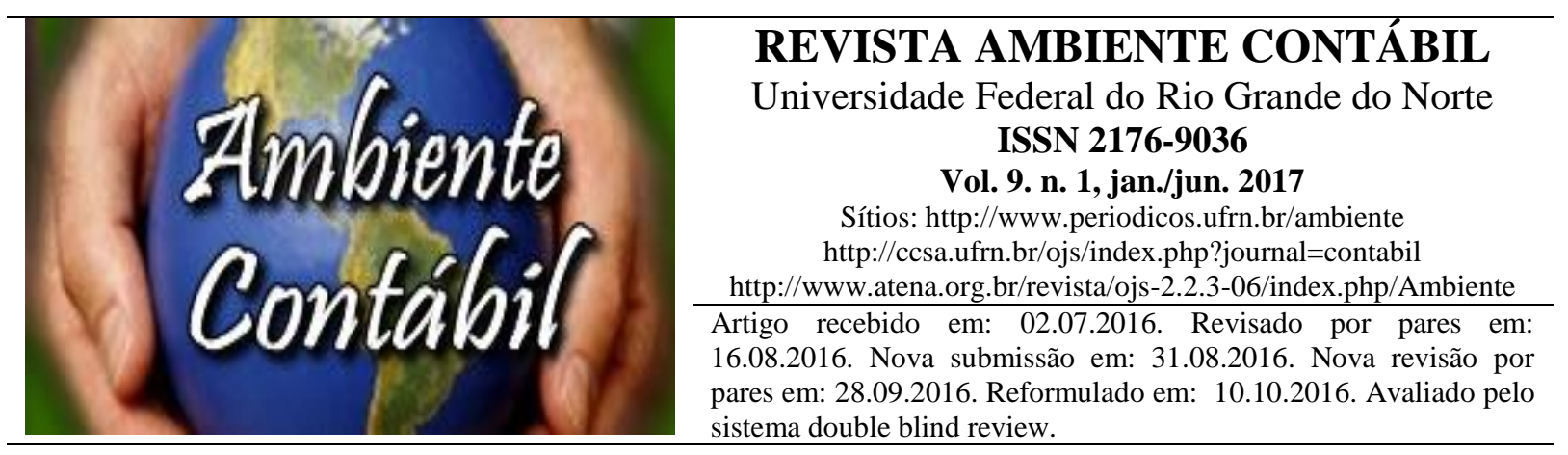

\title{
SISTEMA DE CUSTO BASEADO NA METODOLOGIA DO CUSTEIO TDABC: UMA EXPERIÊNCIA EM UMA ENTIDADE DE APOIO
}

\section{SYSTEM BASED ON COST OF COSTING METHODOLOGY TDABC: AN EXPERIENCE IN A SUPPORT ORGANISATION}

\section{LOS COSTES DEL SISTEMA BASEADO NA METODOLOGIA TDABC: UNA EXPERIÊNCIA EM ORGANIZACIÓN DE SOPORTE}

Autoras

\begin{abstract}
Maria Denise Nunes Rodrigues
Professora do Instituto Federal do Ceará - Campus Quixadá. Mestra em Controladoria (UFC). Endereço: Estrada do Açude do cedro, KM 5 S/N - Cedro - CEP 60020180 - Quixadá, CE -

Brasil - Telefone: (88) 34120111.

E-mail: denuner@yahoo.com.br
\end{abstract}

\section{Ruth Carvalho de Santana Pinho}

Professora da Universidade Federal do Ceará, Faculdade de Economia, Administração, Atuária, Contabilidade e Secretariado Executivo. Doutora em Educação (UFC). Endereço: Av. da Universidade, 2486 - Benfica - CEP60020-180 - Fortaleza, CE - Brasil - Telefone: (085) 33667817.

E-mail: rcspinho@ufc.br

\begin{abstract}
RESUMO
A parceria entre Universidades e entidades de apoio visa conceder agilidade e flexibilidade necessárias ao desenvolvimento de projetos de ensino, pesquisa e extensão. A necessidade de aprimorar os critérios para aceitação de projetos que, via de regra, têm taxas de administração majoradas pelos contratos firmados com as Universidades e a necessidade de manter informações que eventualmente possam ser requeridas pelos órgãos de controle são os fatores que instigaram esta pesquisa. Por conseguinte, o presente estudo tem como objetivo analisar os benefícios resultantes da aplicação de um modelo de apuração de custos à luz do TimeDriven Activity-Based Costing (TDABC), em uma entidade de apoio. Elegeu-se o estudo de caso como estratégia de pesquisa, classificada como exploratória quanto aos objetivos, qualitativa quanto à natureza, e documental quanto aos procedimentos, agregando também a observação participante. O desenvolvimento do modelo de apuração de custos compreendeu as seguintes etapas: identificação dos setores envolvidos; entrevistas com a gerência para o levantamento das atividades e respectivos tempos; obtenção de informações de natureza contábil-financeira acerca dos custos por operações, e por fim a aplicação do modelo de apuração dos custos. Conclui-se que a utilização do TDABC permitirá que a entidade de apoio projete a receita necessária para atender às necessidades do Curso e assegure a
\end{abstract}


consecução dos seus objetivos estratégicos mediante a análise de viabilidade dos projetos que administra. Adicionalmente, a adoção do TDABC propicia o redimensionamento das atividades pela eliminação das que não agregam valor ao negócio e permite às instituições de apoio adequar-se às variações das mensalidades que possam decorrer da possível inadimplência dos alunos, já que estas são a base de cálculo da taxa administrativa. Ademais, o levantamento desses custos permitirá a prestação de contas dos recursos administrados e fundamentará respostas para eventuais questionamentos dos órgãos de controle quanto aos percentuais cobrados a título de taxa de administração.

Palavras-chave: Custos. Time Model Driven. Entidade de Apoio.

\begin{abstract}
The partnership between universities and entities to support aims to provide agility and flexibility needed to develop projects for teaching, research and extension. The need to improve the criteria for acceptance of projects that usually have rates of administration increased by contracts with the universities and the need to maintain information that may be required by the control organs are the factors that instigated this research. The case study classified as a research strategy, exploratory about the objectives, qualitative as to the nature, and documentary about the procedures, incorporating also the participant observation. The development of the model calculation of costs included the following steps: identification of involved sectors, interviews with management to survey the activities and respective times; obtaining information from an accounting nature, financial about costs for operations, and finally the application of the model to calculate the costs. It is concluded that the use of the TDABC will allow the entity to support project the revenue necessary to meet the needs of the course and ensure the achievement of its strategic objectives through the analysis of the feasibility of projects that administers. Additionally, the adoption of the TDABC provides the scalability of the activities by eliminating those that do not add value to the business and allows entities to support adapt to variations in tuition fees that may arise from the possible defaults of students, since these are the basis for the calculation of rate of administration. Moreover, the lifting of these costs will allow the rendering of accounts of the resources managed and provide answers to any questions of control organs as the percentages charged by way of administration fee.
\end{abstract}

Keywords: Costs. Time Model Driven. Support Entity

\title{
RESUMEN
}

La asociación entre universidades y entidades de apoyo está encaminado a proporcionar la agilidad y la flexibilidad necesarias para desarrollar proyectos de docencia, investigación y extensión. La necesidad de mejorar los criterios de aceptación de proyectos que suelen tener tasas de administración aumentaron los contratos con las universidades y la necesidad de mantener la información que pueda ser requerida por los órganos de control son los factores que han impulsado esta investigación. Eligió ele studio de caso como estrategia de investigación exploratoria, clasificados como de los objetivos cualitativos a la naturaleza, y el documental acerca de lós procedimientos, incorporando también la observación participante. El desarrollo del modelo de cálculo de costes incluye los pasos siguientes: identificación de los sectores involucrados, entrevistas con la administración en la encuesta de las actividades y los respectivos tiempos; la obtención de información de carácter contable, financiera acerca de los costos de las operaciones y, por último, la aplicación del modelo para calcular los costos. Se concluye que el uso de la TDABC permitirá a la entidad para el proyecto de apoyo a los ingresos necesarios para satisfacer las necesidades del curso y garantizar el logro de sus objetivos estratégicos mediante el análisis de la viabilidad de los proyectos que administra. Además, la adopción de la TDABC proporciona la escalabilidad de las actividades eliminando aquellos que no agregan valor al negocio y permite a las instituciones de apoyo a adaptarse a 
las variaciones en las tasas de matrícula que pueden derivarse de los posibles incumplimientos de los estudiantes, ya que estos son la base para el cálculo de la tasa administrativa. Además, el levantamiento de estos costes permitirá la rendición de cuentas de los recursos gestionados y proporcionar respuestas a cualquier pregunta de los órganos de control como los porcentajes aplicados por medio de honorarios de administración.

Palabras clave: Costes. Modelo de tiempo. Entidad de Apoyo.

\section{INTRODUÇÃO}

A gestão contemporânea não pode prescindir do conhecimento dos custos do respectivo processo de produção ou prestação de serviços. Os métodos de custeio tradicionais, cuja ênfase é a identificação e o registro dos custos diretos, ao longo do tempo, deixaram de atender a esta necessidade, tendo em vista que o aumento do volume dos custos indiretos demandou informações mais precisas sobre estes (BARROS; SIMÕES, 2014). No serviço de gerenciamento de cursos de pós-graduação a maior parte dos custos enquadra-se como indiretos, sendo identificáveis, apenas, os custos com pessoal. Por conta dessa característica, destaca-se como uma das atividades demandantes dessas outras formas de custeio, dentre as quais, destaca-se o Activity-Based Costing (ABC).

Segundo Kaplan e Anderson (2007), os diversos métodos de custeio sempre encerram em si, algumas distorções. Alguns destes comportam-nas em nível mais elevado, outros em um nível menor. Ressaltem-se as informações distorcidas trazidas pelos critérios de rateio (JONHSON; KAPLAN, 1987; WICKRAMASINGHE; ALAWATTAGE, 2007) e informações distorcidas sobre rentabilidade do cliente (KAPLAN; ANDERSON, 2007). A estas distorções peculiares, agregam-se algumas dificuldades normais, tais como as enfrentadas pelas empresas prestadoras de serviço que precisam atender demandas específicas dos contratantes e, consequentemente, projetar as condições ideais de realização dos diversos serviços.

Geralmente, a implantação de sistemas para atender estas finalidades encerra custos elevados e certa complexidade tecnológica para, ao final, estabelecerem apenas o custo dos serviços que presta. As inquietações se acentuam quando da necessidade de utilizar essas informações como base para controle e prestação de contas, situação encontrada envolvidas as entidades de apoio às Universidades.

As entidades de apoio são instituições criadas com o fito de dar apoio a projetos de pesquisa, ensino, extensão e desenvolvimento científico e tecnológico, de interesse das universidades federais e instituições de ensino superior, públicas ou privadas. A existência das entidades de apoio visa à agilidade administrativa, e em alguns casos, principalmente, à remuneração justa de professores e pesquisadores que empreendem um esforço laboral, além da sua carga horária de trabalho normal (BRASIL, 1994).

Para exercer suas atividades de apoio, referidas entidades são remuneradas pela taxa de administração, isto é, uma espécie de comissão, contratualmente assegurada, capaz de dar à esta, um percentual sobre as receitas arrecadadas na prestação do serviço para a Universidade.

Observações empíricas identificaram inúmeras críticas, lançadas sobre este tipo de entidade, começando pela possível oneração da Universidade dada a forma de cálculo da taxa, a qual aumenta à medida que o projeto envolva um volume maior de recursos, passando por questões ligadas à forma jurídica de constituição e chegando ao controle dos recursos públicos. Em contrapartida, os recorrentes cortes no orçamento e o aumento dos custos têm levado algumas Universidades a apurarem déficits que na prática significam a redução progressiva dos recursos para funcionamento de alguns cursos e da estrutura administrativa. Dadas as dificuldades, uma das saídas é a obtenção de receitas fora do orçamento, alternativa esta encontrada na cobrança de alguns cursos de extensão e pós-graduação. 
Entendendo que a Lei Federal $n^{\circ}$ 8.958/94 (BRASIL, 1994) prevê a possibilidade apenas de as fundações apoiarem os projetos de pós-graduação "e não assumirem inteiramente a sua execução, suprimindo a sua gratuidade e inserindo a capacidade de pagamento como critério de acesso", a representação do Ministério Público Federal no Distrito Federal e em outros estados, como Ceará e Rio de Janeiro, ajuizaram ações civis públicas para suspender a cobrança de taxas e mensalidades em cursos de pós-graduação oferecidos por Universidades federais. No Ceará, especificamente, desde 2012, estes cursos foram suspensos, permanecendo apenas turmas que já estavam em funcionamento ou com o projeto já aprovado nas instâncias da Universidade (UFC, 2016).

A medida, a princípio suscitou discussão, mas arrefeceu ao longo do tempo. A Proposta de Emenda Constitucional que prevê a possibilidade de cobrança de cursos de extensão e pósgraduação pelas Universidades federais, de autoria do deputado Cleber Verde (PRB - MA), ou seja, a PEC 395/14, aprovada em 21 de outubro de 2015, cuja votação dos destaques ocorrida em 17/02/2016 retirou do texto base os mestrados profissionais e aguarda votação em segundo turno, reabriu o espaço para reflexão sobre as entidades de apoio (CÂMARA DOS DEPUTADOS, 2016).

Posto isto, e considerando a retomada desta atividade, é possível enquadrar as entidades de apoio na categoria de entidades que reclamam para si, informações de custos mais precisas que lhes permitam não só gerar uma informação adequada para determinação do valor do serviço, bem como responder a questionamentos que possam vir dos órgãos de controle e de coordenadores de cursos. Assumindo-se que a escolha do método de custeio depende dos objetivos gerenciais e das características operacionais da entidade, configurou-se o seguinte problema de pesquisa: Quais os benefícios advindos da aplicação do método Time-Driven Activity-Based Costing (TDABC) para o gerenciamento de um curso de pós-graduação por uma entidade de apoio?

Em pesquisa, pressupostos são respostas temporárias ao problema de pesquisa que se antepõem ao processo investigativo. Assim, pressupõe-se que a apuração de custos por meio da aplicação do método de custeio TDABC em uma entidade de apoio oferece os elementos necessários para a adequada tomada de decisões quanto à aceitação de projetos, tendo em vista que a Universidade apoiada majora contratualmente a taxa de administração.

Estudos bibliométricos, tais como o de Schultz et al. (2004), apontam para a escassez de produção científica da área de custos com ênfase em empresas prestadoras de serviços, pelo que predomina a atividade industrial. Adicionalmente, cumpre destacar a pesquisa de Santana, Afonso e Fagundes (2015) que revela que entre 2008 e 2012 foram produzidos apenas treze artigos sobre TDABC, incluindo eventos ou periódicos nacionais e estrangeiros. Entre 2005 e 2007, apenas quatro (SOUZA; AVELAR; BOINA; LARA, 2009).

Constata-se ainda que o empenho de boa parte das pesquisas tem sido o de alinhar o método de custeio a uma corrente estratégica (SHANK e GOVINDARAJAN, 1997; CUNNINGHAM, 1992; FRY, STEELE e SALADIN, 1994). Encontram-se ainda trabalhos voltados para eficácia do custeamento pelo TDABC, tais como, o de Eckert et al. (2012) que abordam o TDABC em uma empresa de mármores sob encomenda; o de Rodrigues, Silva e Araújo (2014) em uma instituição particular de ensino superior; e o de Wernke, Lembeck e Mendes (2009) que estudaram o método em uma empresa transportadora, comparando-o ao Ativicty-Based Cost (ABC). Esforços que associem o método de custeio às necessidades de controle não foram identificadas quando realizado o levantamento bibliográfico.

Ante o exposto e com vistas a responder à questão da pesquisa, teve-se como objetivo geral, analisar os benefícios resultantes da aplicação de um modelo de apuração de custos à luz do Time-Driven Activity-Based Costing (TDABC). Para o atingimento deste, foram estabelecidos os seguintes objetivos específicos: identificar os setores envolvidos para mapeamento das atividades realizadas pela entidade; obter informações de natureza contábil- 
financeira acerca dos custos dessas operações; e aplicar o modelo de apuração de custos usando a planilha Excel®.

A estrutura do artigo que ora se apresenta é composta por mais quatro seções, além desta primeira. A segunda trata da construção teórica que sustenta o método TDABC; a terceira seção apresenta a metodologia desenvolvida para realização desta investigação; e, a quarta aborda os dados levantados pela pesquisa, bem como a análise dos resultados. Por fim, a quinta seção traz as principais conclusões com vistas a responder ao problema de pesquisa e confirmar o pressuposto. Sendo o objeto, elemento-chave para definição dos contornos da pesquisa, acredita-se que referida estrutura está em conformidade com o que se busca alcançar com esta investigação.

\section{REFERENCIAL TEÓRICO}

Hodiernamente, nenhuma entidade, independente de segmento ou porte, pode se escusar de pautar suas ações por uma conduta estratégica, contudo, "a estratégia não existe, de fato, como proposta meramente teórica; ela só se realiza na prática" (DIEHL; GONÇALO, 2005). $\mathrm{O}$ processo estratégico, de forma geral, abarca as funções de planejamento, execução e controle. O planejamento, segundo Chiavenato (1995), busca determinar antecipadamente o que se deve fazer e quais objetivos devem ser alcançados, e visa proporcionar condições racionais para que se organize e dirija a empresa. O controle, conforme Koontz e O'Donnel (1998), consiste em medir e corrigir o desempenho dos colaboradores para assegurar que os objetivos da empresa e os planos delineados para alcançá-los sejam realizados; permitir decidir o rumo dos negócios, auxiliando em tomada de decisões mais adequadas aos seus interesses.

Em qualquer abordagem estratégica adotada, os sistemas de custos são ferramentas para viabilizar as diretrizes estratégicas. A forma efetiva de calculá-los tem por base os sistemas ou métodos de custeio. Os métodos de custeio tradicionais são o custeio por absorção e o custeio direto. Com as mudanças ocorridas no cenário mundial, metodologias de apuração e gestão de custos, mais sofisticadas e com visão gerencial, surgiram e se aperfeiçoaram. Dentre estas, o Custeio Baseado em Atividades, Activity-Based Costing (ABC), que é um método aplicável a qualquer tipo de organização que, mesmo tendo origem nas fábricas, muitas organizações que prestam serviços também obtêm benefícios com o seu uso (KAPLAN; COOPER, 2000).

\subsection{MÉTODO DE CUSTEIO POR ATIVIDADES}

$\mathrm{O}$ ABC é um método pelo qual os custos indiretos de fabricação e as despesas são atribuídos, inicialmente, às atividades, para só então serem alocados aos produtos/serviços ou outros objetos de custo, por meio dos direcionadores de custos. Um direcionador de custo (cost driver) é utilizado como fator de associação entre os recursos e as atividades custeadas ou entre as atividades e os objetos custeados (SANTANA; COLAUTO; CARRIERI, 2013). O método de custeio ABC vem, segundo Fontoura (2013), sendo amplamente discutido no meio acadêmico e nas organizações preocupadas em otimizar processos e identificar atividades que não agregam valor ao negócio, consoante um processo de definição estratégica.

Barros e Simões (2014) enfatizam o poder do ABC enquanto ferramenta de gestão para aumento da rentabilidade da empresa. Por um lado, os autores referem que a informação procedente do $\mathrm{ABC}$ permite que as organizações alterem as estratégias de preço e o mix de produtos e clientes como forma de exceder os custos incorridos. Por outro lado, e adicionalmente, o ABC ajuda os gestores a reduzir o consumo de recursos.

Para os autores, o sistema ABC evidencia para os gestores informações que direcionam a atenção de gerenciamento para as atividades responsáveis pelo custo do serviço. Desta forma, possibilita identificar os impactos causados pela decisão e controle dos custos, bem como permitir melhor administração das atividades visando segregar as que agregam valor 
das demais. Em suma, o sistema $\mathrm{ABC}$ busca reduzir o custo por meio da eliminação dos desperdícios. Por conseguinte, por intermédio da gestão dos custos obtém-se uma otimização nos retornos financeiros, aliado à qualidade dos serviços oferecidos pela empresa.

O método de custeio adotado pela gestão aponta para o modelo de análise de rentabilidade que será estabelecido para os produtos ou serviços, bem como para os clientes (PADOVEZE; TAKAKURA JR., 2013). Os modelos de análise de rentabilidade construídos a partir do custeio variável e, consequentemente, da margem de contribuição, se mostram ineficientes quando se trata de prestação de serviços diferenciados a cada novo projeto. Desta observação, busca-se uma resposta para esta necessidade gerencial, pelo que o ABC parece atender melhor.

Esta percepção se sustenta na visão de Fontoura (2013) segundo a qual um método de custeio deve atender às necessidades de informação da empresa. Estrategicamente, a proposta de um método de custeio deve ser oferecer além dos resultados contábeis e financeiros. Nesta perspectiva, o $\mathrm{ABC}$ conduz ao conhecimento do processo operacional e instiga ao aprofundamento em questões que passam ao largo dos relatórios contábeis.

A despeito das vantagens supramencionadas, o modelo $\mathrm{ABC}$ falhou em fornecer, à maioria das organizações, um sistema de custeio eficaz e sustentável ao mesmo tempo, pelas dificuldades de implementação e manutenção (TSE; GONG, 2009; SOUZA et al., 2010; HOOZÉE; BRUGGEMAN, 2010). Por outro lado, os motivos que levaram à busca por eliminar as informações distorcidas acerca das operações internas, as quais tiveram o papel de impulsionar a criação de métodos, tais como o $\mathrm{ABC}$, são os mesmos que estão subjacentes à resistência ao método, a saber, a subordinação dos dados aos relatórios de Contabilidade Financeira, ou seja, a sua não vinculação direta à Contabilidade para fins de publicação. $\mathrm{O}$ viés contábil, contudo, não invalida as críticas relacionadas à morosidade, complexidade e elevado volume de dados necessários à implantação do $\mathrm{ABC}$.

\subsection{TIME DRIVEN ACTIVITY - BASED COSTING}

Visando à superação das dificuldades retromencionadas, Kaplan e Anderson (2004) criaram o Time Driven Cost, o qual concede às organizações uma opção simples e prática para determinar o custo e a capacidade utilizada dos processos, bem como, a rentabilidade de produtos e clientes (BARROS e SIMÕES, 2014). À época, os idealizadores do sistema identificaram um problema, qual seja o pressuposto do uso dos recursos em capacidade plena. As operações, geralmente são realizadas abaixo da capacidade total, pelo que, este equivocado pressuposto possibilita que os direcionadores de custos estejam superestimados.

Desta forma, o time driven cost, com uma abordagem simplificada, segundo Kaplan e Anderson (2004), define uma estimativa teórica de utilização do tempo que fica em torno de $80 \%$ para atividades-homem e $85 \%$ para operações-máquina do potencial produtivo. Esta compreensão culminou no custeio pelo Time Driven Activity-Based Costing (TDABC). Para Kaplan e Anderson (2007, p. 26), o TDABC "usa o tempo para direcionar os cursos dos recursos diretamente aos objetos de custos, como transações, pedidos, produtos, serviços e clientes".

Assim, o TDABC aloca os custos aos objetos de custeio com base em unidades de tempo consumidas pelas atividades. Desta forma, o tempo é visto como um cost driver primário para a alocação de custos aos objetos de custeio, uma vez que a maioria dos recursos, como mão de obra, equipamento e instalações possuem capacidades que podem ser mensuradas em termos de tempo (NAMAZI, 2009; DALCI et al., 2010). Deste modo, identificou-se no time-driven model uma alternativa no sentido de minimizar o nível de arbitrariedade implícito em todos os modelos de custeio para subsidiar o modelo de apuração dos custos em uma entidade de apoio. A adoção deste direcionador resultou da busca de um 
modelo que melhor atendesse às necessidades informacionais das empresas e considerasse as limitações existentes quando da aplicação do ABC.

A seguir, buscando alcançar os objetivos propostos para essa pesquisa, apresentam-se os aspectos metodológicos que orientaram o estudo. Cumpre destacar que o delineamento foi estabelecido a partir de uma problemática real, identificada na atividade exercida pela entidade escolhida como unidade de estudo.

\section{METODOLOGIA}

A concepção deste modelo de apuração de custos caracteriza-se como pesquisa qualitativa quanto à natureza e exploratória quanto aos objetivos. Quanto aos procedimentos, bibliográfica, para identificação do referencial teórico que melhor amparasse a solução que o problema requisitava; documental, tendo em vista a obtenção das informações necessárias acerca das operações da empresa e observação participante, pelo fato das pesquisadoras serem professoras associadas da entidade, o que propiciou um conhecimento específico do processo de gerenciamento dos cursos e das relações com a entidade apoiada. Ademais, identificou-se na literatura o necessário para referida empreitada, pelo que foram estabelecidas as etapas necessárias para realização do trabalho.

A entidade de apoio escolhida para o desenvolvimento da pesquisa foi a Associação Cearense de Estudos e Pesquisas (ACEP), responsável pela administração de parte dos cursos de pós-graduação, lato e stricto sensu, da Universidade Federal do Ceará (UFC). Fundada em 1997, a ACEP atua na gestão de cursos, elaboração de estudos e pesquisas de cunho técnico ou científico, na realização de concursos em nível federal, estadual e municipal, bem como em atividades de consultoria, diagnósticos de gestão, cursos e treinamentos. Possui corpo de associados formado por professores, técnicos, alunos e ex-alunos da Faculdade de Economia, Administração, Atuária, Contabilidade e Secretariado Executivo (FEAAC) da UFC.

A etapa inicial da pesquisa consistiu na elaboração de roteiros de entrevistas a serem aplicados aos gerentes de cada setor. As entrevistas visavam identificar as atividades e fazer um levantamento mensal dos respectivos tempos gastos, com atividades de gerenciamento dos cursos, de forma a subsidiar o modelo de apuração a ser desenvolvido, haja vista que a arrecadação da taxa de administração também tem periodicidade mensal. Neste ínterim, obteve-se ainda, informações de natureza contábil quanto aos custos despendidos pela entidade. Levantadas informações necessárias, passou-se à análise destas para aplicação do modelo.

\section{APLICAÇÃO DO MODELO COM BASE NO TDABC}

Nesta seção apresentam-se os resultados da aplicação do modelo baseado no TDABC para apuração do custo da prestação do serviço de gerenciamento dos recursos financeiros de um curso de pós-graduação realizado por uma entidade de apoio à Universidade Federal do Ceará. Primeiramente, buscou-se identificar os setores e mapear as respectivas atividades desenvolvidas, conforme demonstrado no Quadro 1. 


Quadro 1 - Setores e suas atividades
\begin{tabular}{|l|l|}
\hline \multicolumn{1}{|c|}{ SETORES } & \multicolumn{1}{c|}{ ATIVIDADES } \\
\hline \multirow{4}{*}{ Projetos } & Revisão do projeto do curso \\
\cline { 2 - 2 } & Divulgação \\
\cline { 2 - 2 } & Processo seletivo \\
\cline { 2 - 2 } & Fechamento de contratos \\
\hline \multirow{2}{*}{ Controladoria } & Acompanhamento de orçamentos \\
\cline { 2 - 2 } & Prestação de Contas \\
\hline \multirow{2}{*}{ Contabilidade } & Registro dos fatos contábeis \\
\cline { 2 - 2 } & Emissão de relatórios contábeis \\
\hline \multirow{3}{*}{ Financeiro } & Contas a pagar \\
\cline { 2 - 2 } & Contas a receber \\
\cline { 2 - 2 } & Arquivo \\
\hline
\end{tabular}

Fonte: Elaborada pelas autoras.

Das atividades mapeadas foram identificadas aquelas necessárias para oferta, realização e finalização de um curso de pós-graduação, ressaltando que tais atividades abrangem desde a procura da entidade de apoio pelo coordenador para gerenciar os recursos financeiros até, a prestação de contas desses recursos para a Universidade. Desse modo, o primeiro contato é com o setor de projetos, o qual revisa o projeto do curso, ficando responsável por avaliar e aprovar o material para divulgação do curso para o mercado, organizar o processo seletivo dos interessados e por último, fechar os contratos com os aprovados na seleção. Ressalte-se que as atividades do setor de projetos constituem-se na orientação ao trabalho do coordenador, responsável direto pelo Curso.

Após essa etapa e durante a realização do curso, o trabalho da entidade de apoio, envolve os setores financeiros, contabilidade e controladoria, os quais são responsáveis, respectivamente, pela entrada e saída de caixa; registro dos dados contábeis para emissão de relatórios contábeis; e acompanhamento do planejado com o que foi executado para realização da prestação de contas dos recursos financeiros despendidos em cada curso.

Foram identificados, na sequência, os custos envolvidos nos setores, consoante a forma de apropriação destes ao serviço prestado, assim delimitados:

a) Diretos, que englobam os gastos com pessoal e abrangendo valores tais como, vencimentos, encargos e benefícios recebidos pelos colaboradores; e

b) Indiretos, que envolvem a infraestrutura, tais como, aluguel, energia, telefone e internet; sistemas informatizados compreendendo os programas financeiro e contábil para registro das informações; e por fim, prestação de serviços que se refere às atividades de apoio, a saber, assessoria jurídica, contábil e serviços de manutenção.

Os gastos indiretos foram apropriados aos setores conforme o número de colaboradores lotados em cada um. Os dados apresentados na Tabela 1 foram extraídos dos relatórios contábeis, referentes ao período de agosto de 2015.

Tabela 1 - Gastos mensais alocados por item e setores

\begin{tabular}{llcccc}
\hline \multicolumn{1}{c}{ Gastos } & Grupo & Projetos & Controladoria & Contabilidade & Financeiro \\
\hline Diretos & Pessoal & $4.501,64$ & $3.275,86$ & $3.227,67$ & $5.585,82$ \\
& & & & & \\
\hline \multirow{2}{*}{ Indiretos } & Infraestrutura & $3.514,22$ & $2.342,81$ & $2.342,81$ & $4.685,63$ \\
& Sistemas Informatizados & 193,88 & 129,25 & 129,25 & 258,50 \\
& Prestação de Serviços & $6.753,58$ & $4.502,38$ & $4.502,38$ & $9.004,77$ \\
\hline \multirow{2}{*}{ Total } & & $\mathbf{1 4 . 9 6 3 , 3 1}$ & $\mathbf{1 0 . 2 5 0 , 3 1}$ & $\mathbf{1 0 . 2 0 2 , 1 2}$ & $\mathbf{1 9 . 5 3 4 , 7 1}$ \\
\hline
\end{tabular}

Fonte: Elaborada pelas autoras 
Com a identificação do número de colaboradores envolvidos em cada atividade, calculou-se a capacidade padrão e a capacidade total de cada atividade/departamento, mediante a multiplicação do número de funcionários pela quantidade de dias e de minutos. Para este cálculo considerou-se que a capacidade total é de 21 dias úteis por mês e 6 horas (360 min) por dia. Considerando por sua vez, uma taxa eficiência do tempo de $80 \%$ (KAPLAN; ANDERSON, 2007), a capacidade padrão é de 21 dias úteis por mês e 5,1 horas (306 min) por dia. Na Tabela 2 apresentam-se a capacidade padrão e capacidade total.

\section{Tabela 2 - Cálculo da capacidade padrão e total por setores}

\begin{tabular}{lccccc}
\hline \multicolumn{1}{c}{ Itens } & Projetos & Controladoria & Contabilidade & Financeiro & Total \\
\hline Número de Funcionários & 3 & 2 & 2 & 4 & 11 \\
Capacidade Total (min) & 22.680 & 15.120 & 15.120 & 30.240 & 83.160 \\
Capacidade Padrão (min) & 18.144 & 12.096 & 12.096 & 24.192 & 66.528 \\
\hline
\end{tabular}

Fonte: Elaborada pelas autoras

Com o cálculo da capacidade padrão foi possível mensurar a taxa de custo unitário por departamento, conforme evidenciado na Tabela 3. Esta taxa é obtida pela razão entre os gastos despendidos nos setores e as respectivas capacidades padrão.

Tabela 3 - Taxa de custo unitário padrão da capacidade por setor

\begin{tabular}{lrrrr}
\hline \multicolumn{1}{c}{ Itens } & Projetos & Controladoria & Contabilidade & Financeiro \\
\hline Gasto anual por setor & $14.963,31$ & $10.250,31$ & $10.202,12$ & $19.534,71$ \\
Capacidade Padrão (min) & 18.144 & 12.096 & 12.096 & 24.192 \\
Taxa do custo unitário (R\$/min) & 0,82 & 0,85 & 0,84 & 0,81 \\
\hline
\end{tabular}

Fonte: Elaborada pelas autoras.

No tocante ao cálculo do tempo despendido por atividades foi solicitado aos responsáveis pelos setores que estimassem o tempo dedicado a cada atividade necessária para gerenciamento dos recursos financeiros de um curso de pós-graduação. No Quadro 2 estão evidenciadas as atividades realizadas de cada setor com a sua respectiva estimativa mensal de tempo.

Quadro 2 - Atividades e tempo despendido

\begin{tabular}{|c|l|c|}
\hline SETORES & \multicolumn{1}{|c|}{ ATIVIDADES } & Tempo (min) \\
\hline \multirow{4}{*}{ Projetos } & Revisão do projeto do curso & 60 \\
\cline { 2 - 3 } & Acompanhamento do projeto do curso & 60 \\
\cline { 2 - 3 } & Divulgação & 15 \\
\cline { 2 - 3 } & Processo seletivo & 60 \\
\cline { 2 - 3 } & Fechamento de contratos & 30 \\
\hline \multirow{2}{*}{ Controladoria } & Acompanhamento de orçamentos & 60 \\
\cline { 2 - 3 } & Prestação de Contas & 240 \\
\hline \multirow{2}{*}{ Contabilidade } & Registro dos fatos contábeis & 30 \\
\cline { 2 - 3 } & Relatórios contábeis & 60 \\
\hline \multirow{3}{*}{ Financeiro } & Contas a pagar & 60 \\
\cline { 2 - 3 } & Contas a receber & 60 \\
\cline { 2 - 3 } & Arquivo & 30 \\
\hline
\end{tabular}

Fonte: Elaborada pelas autoras.

Tomando por base as informações sobre os tempos estimados, foi necessário determinar o tempo total gasto para prestação do serviço. Para isso, foram somados os tempos despendidos por cada uma das atividades e este total, multiplicado pela taxa do custo unitário (Tabela 3) para mensurar o custo da prestação do serviço de gerenciamento dos recursos financeiros de um curso de pós-graduação. 
Tabela 4 - Custo da Prestação do Serviço

\begin{tabular}{lccc}
\hline \multicolumn{1}{c}{ Setores } & Tempo & Taxa do Custo Unitário & Custo total \\
\hline Projetos & 165 & 0,82 & 135,30 \\
\hline Custo Inicial por curso & & & $\mathbf{1 3 5 , 3 0}$ \\
\hline Projetos & 60 & 0,82 & 49,20 \\
Controladoria & 300 & 0,85 & 255,00 \\
Contabilidade & 90 & 0,84 & 75,60 \\
Financeiro & 150 & 0,81 & 121,50 \\
\hline Custo Mensal por curso & & & $\mathbf{5 0 1 , 3 0}$ \\
\hline
\end{tabular}

Fonte: Elaborada pelas autoras.

A Tabela 4 apresenta o custo arcado pela entidade de apoio quando iniciado o processo de oferta do curso. Esse custo ocorre uma única vez em cada curso e envolve as atividades de revisão do projeto, divulgação, processo seletivo e fechamento de contrato. Nesta é demonstrado também, o custo mensal durante a realização do curso. Assim, observase que os custos de gerenciamento dos recursos financeiros de um curso de pós-graduação inicial e mensal são 135,30 e de R \$ 501,30, respectivamente.

\section{ANÁLISE DE RESULTADOS}

A estratégia consiste na definição de meios para alcançar um objetivo ou fim específico. No caso das entidades de apoio, a estratégia está no entorno de oferecer um serviço de qualidade, sem perder o foco da viabilidade financeira desse serviço e o adequado controle.

Da aplicação do modelo ora proposto, cuja operacionalização se dá em bases monetárias verificáveis, extraem-se as condições para manutenção estratégica dessas entidades, as quais precisam desta base para avaliar a aceitação do serviço, bem como servir para controle e prestação de contas do uso dos recursos financeiros para a instituição contratante.

As entrevistas revelaram que uma entidade de apoio faz mais do que o simples controle de recursos. Estas são responsáveis pela revisão dos projetos pedagógicos de cursos que serão submetidos às instâncias da Universidade, bem como, orienta a divulgação dos cursos e a seleção dos alunos, constituindo-se a interface entre o público e a instituição de ensino, pois, o aluno só tem contato com a Universidade a partir do processo de matrícula, passando antes pela etapa do fechamento dos contratos com a entidade.

Ressalte-se que além da prestação de contas, todas as informações requeridas pelos órgãos de controle interno e externo são direcionadas para a entidade de apoio. Suas atividades são também, alvo das ações da unidade de auditoria interna da Universidade. A entidade também responde, em primeira instância, a demandas administrativas e judiciais emanadas dos alunos e oferece consultoria aos coordenadores de cursos nestes casos.

O Quadro 1 foi elaborado para demonstrar os setores diretamente envolvidos com a prestação de serviço em tela e sintetiza as principais atividades desenvolvidas por cada um destes. Em seguida, foram identificados os gastos agregados por setores, evidenciando os gastos indiretos como os mais representativos, com cerca de $70 \%$ do total (Tabela 1).

Este aspecto ratifica o posicionamento de Padoveze, Takakura Jr.(2013) e Fontoura (2013), assinalando para a necessidade de um método que busque amenizar as distorções na mensuração dos custos, oriundas da subjetividade que permeia os custos indiretos quando da apropriação ao serviço prestado. Fato este também verificado por Wernke, Lembeck e Mendes (2009). 
No tocante à Tabela 2, nota-se que de uma capacidade total de 83.160 minutos por mês são despendidos 66.528 minutos como capacidade padrão para efetiva realização das atividades relacionadas à prestação do serviço. Vale ressaltar que a mensuração da capacidade padrão levou em consideração as características da entidade a qual se adaptou às considerações do cálculo proposto pelo método TDABC de Kaplan e Anderson (2004).

No que diz respeito à Tabela 3 , não obstante as taxas dos custos unitários serem bem próximas, nota-se que os setores Projetos e Financeiro apresentam maiores volumes de gastos e de horas consumidas na prestação de serviços. Fato este que se justifica pelas exigências da Universidade na adequação dos projetos dos cursos conforme legislações internas e pelo fluxo intenso de pagamentos e recebimentos durante todo o curso, envolvendo horas-aula, encargos, tributos, compra de material didático e de expediente, entre outros.

No Quadro 2 evidenciou-se os tempos estimados na realização das atividades, os quais serviram de base para mensuração do custo por setor para efetiva prestação do serviço. Denota-se que, o setor da Controladoria obteve o maior custo (Tabela 4), já que as atividades desenvolvidas por este setor demandam um tempo maior para realização, haja vista a obrigatoriedade do acompanhamento da execução do orçamento e da prestação de contas dos recursos financeiros dos cursos.

A Tabela 4, por sua vez, apresenta o custo para o gerenciamento de um curso em nível de pós-graduação. O custo foi desdobrado em inicial e mensal, pelo fato do custo inicial ocorrer uma única vez. Outrossim, este processo pode ser descontinuado, à medida que não haja demanda pelo curso.

Observou-se que a Universidade não desembolsa nenhum valor, assim os cursos são iniciados com recursos próprios da entidade. Caso haja êxito haverá o ressarcimento dos valores consoante previsão orçamentária. Não obstante, muitas vezes, os cursos não atingem o número mínimo de alunos e não são realizados. Logo, referidos custos com essa etapa constituem-se risco para a entidade de apoio, pois podem ser perdidos.

Observou-se ainda que preocupações com variação da receita, a qual é calculada sobre as mensalidades recebidas no mês, não estavam sendo consideradas pela entidade. Os custos dos serviços são fixos, todavia, o valor da taxa oscila de acordo com adimplência dos alunos, o que pode levar o curso, em determinado momento, a uma situação deficitária.

Cada curso tem características próprias, a saber: quantidade de professores e disciplinas, recursos didáticos e materiais envolvidos, defesa de monografia, composição das bancas examinadoras, entre outros. Por conseguinte, as atividades realizadas por uma entidade de apoio demandam a utilização de um método de custeio que depreenda essas especificidades.

Com o uso do TDABC, os gestores poderão analisar a rentabilidade de cada curso subsidiando a decisão de aceitar a proposta da Universidade, fazer projeções de risco e adotar medidas para mitigá-los, tais como, de combate à inadimplência e também de rediscutir cláusulas contratuais com a entidade apoiada e também com os alunos, no sentido de evitar perdas financeiras.

Outro ponto a ser pensado, tendo em vista as informações extraídas do TDABC, é discutir previamente com os coordenadores de curso, que são os professores que criam ou conduzem o processo nas instâncias da Universidade, aspectos ligados à viabilidade destes, mormente, financeiros e de conformidade com a regulamentação interna e externa, o que permitirá redução de custo e otimização de tempo para as entidades de apoio. 


\section{CONCLUSÃO}

Dadas as especificidades de uma entidade de apoio às Universidades, identificou-se a necessidade de um sistema de custeio que proporcionasse não só a mensuração do custo do serviço, bem como a tomada de decisão relativa à aceitação, manutenção ou rejeição de contratos pertinentes à gestão de cursos de pós-graduação.

Por conseguinte, objetivo do estudo foi analisar os resultados da aplicação de um modelo de apuração de custos à luz do Time-Driven Activity-Based Costing (TDABC) na Associação Cearense de Estudos e Pesquisas, entidade de apoio à Universidade Federal do Ceará. Os objetivos específicos foram identificar os setores envolvidos para mapeamento das atividades realizadas pela entidade; obter informações de natureza contábil-financeira acerca dos custos dessas operações; e aplicar o modelo de apuração de custos usando a planilha Excel®. A consecução destes permitiu às autoras explorarem uma parte do universo das parcerias entre entidades de apoio e as Universidades.

Cumpre destacar que as Universidades não podem desconsiderar a cobrança dos cursos de pós-graduação como uma alternativa para a crise financeira que atravessa o país e consequentemente, seus próprios orçamentos. Isto posto, a atual conjuntura das Universidades Federais e a iminente aprovação de uma emenda constitucional que permitirá a retomada da cobrança de cursos de pós-graduação lato sensu, remetem ao problema de pesquisa sobre o qual se debruça este trabalho.

A fundamentação teórica dos métodos de custeio apontou o TDABC (KAPLAN; ANDERSON, 2007) como a metodologia mais adequada a ser aplicada, para a construção de um modelo de apuração e gestão de custos, uma vez que esta facilita a identificação do total de recursos consumidos por atividades, auxiliando, assim, a definição ou negociação da taxa de administração a ser cobrada nos projetos da Universidade. De forma transversal, este estudo corrobora as conclusões a que chegaram Eckert et al. (2012); Rodrigues, Silva e Araújo (2014); e Wernke, Lembeck e Mendes (2009) quanto à aplicabilidade do TDABC.

$\mathrm{O}$ aumento da subjetividade pelo uso do TDABC apontada por Wernke, Lembeck e Mendes (2009) não se constituiu obstáculo para consecução dos objetivos, haja vista a simplicidade das atividades e o porte da entidade envolvida no estudo. Considerando que o foco do método é a acurácia e não a precisão, os resultados foram satisfatórios. O TDABC oferece condições de identificar o custo da administração de um curso de pós-graduação, de forma simples e clara. Neste ramo de atuação, esta condição é importante, tendo em vista que são administrados, concomitantemente, vários cursos e, a despeito de pertencerem a uma única Universidade, cada um deles tem especificidades que precisam ser consideradas pela entidade de apoio.

Em suma, considerou-se que o escopo definido inicialmente para o trabalho foi plenamente atendido. O estudo confirmou o pressuposto da necessidade de um método de custeio nos moldes do TDABC para atender às necessidades das entidades de apoio. A questão de pesquisa foi respondida ao se apontar os benefícios advindos da aplicação de um método de custeio adequado e relevante.

Conclui-se que a utilização do TDABC permitirá que a entidade de apoio projete a receita necessária para atender às necessidades do Curso e assegure a consecução dos seus objetivos estratégicos mediante a análise de viabilidade dos projetos que administra. Adicionalmente, a adoção do TDABC propicia o redimensionamento das atividades pela eliminação das que não agregam valor ao negócio e permite às instituições de apoio adequarse às variações das mensalidades que possam decorrer da possível inadimplência dos alunos, já que estas são a base de cálculo da taxa administrativa. Ademais, o levantamento desses custos permitirá a prestação de contas dos recursos administrados e fundamentará respostas para eventuais questionamentos dos órgãos de controle quanto aos percentuais cobrados a título de taxa de administração. 
Notadamente, por se tratar de um estudo de caso, os resultados não podem ser extrapolados para outras entidades de apoio, pelo que sugere-se que outros estudos sejam feitos, tendo em vista ser um contexto pouco explorado na literatura.

\section{REFERENCIAS}

BARROS, R. S.; SIMÕES, A. M. D. Do custeio tradicional ao time-driven activity-based costing: revisão de literatura e sugestões de investigação futura. Revista Iberoamericana de Contabilidad e Gestion (RIGC). Vol. XII, nº 24, Julio-Diciembre 2014.

BRASIL. Lei $\mathrm{n}^{\circ}$ 8.958, de 20 de dezembro de 1994. Dispõe sobre as relações entre as instituições federais de ensino superior e de pesquisa científica e tecnológica e as fundações de apoio e dá outras providências. Diário Oficial [da] República Federativa do Brasil. Disponível em: http://www.planalto.gov.br/ccivil_03/leis/18958.htm

BRASIL. Projeto de Emenda Constitucional no. 395. Altera a redação do inciso IV do art. 206 da Constituição Federal, referente à gratuidade do ensino público em estabelecimentos oficiais. Câmara dos Deputados, Brasília, 2014. Disponível em: http://www.camara.gov.br/proposicoesWeb/fichadetramitacao?idProposicao=611966.

Acesso: 14. Jan. 2016.

CHIAVENATO, I. Administração de empresas: uma abordagem contingencial. 3a.edição. São Paulo: Makron, 1995.

CAMPOS, G. F. O.; FIGUEIRÊDO JR., H. S. de. Aplicação do método de custeio ABC direcionado pelo tempo (TDABC) como apoio à gestão de um estaleiro naval. Anais: XVI Congresso Brasileiro de Custos, Fortaleza, 2009.

CUNNINGHAM, G.M. Management control and accounting systems under competitive strategy. Accounting, Auditing \& Accountability Journal, vol.5, No.2, pp. 85-102, 1992.

DALCI, I.; TANIS, V.; KOSAN, L. Customer profitability analysis with time-driven activity based costing: A case study in a hotel. International Journal of Contemporary Hospitality Management, 22 (5): 609-637. 2010.

DIEL, C. A.; GONÇALO, C. R. Gestão estratégica de custos: uma estrutura para análise da estratégia praticada aplicada em empresas de serviços. Anais: IX Congresso Brasileiro de Custos. Florianópolis, 2005.

ECKERT, A.; MECCA, M. S.; BIASIO, R.; MAURO, P. S. A viabilidade da aplicação do método de custeio TDABC em uma empresa de mármores sob encomenda. Anais: IX Congresso Brasileiro de Custos. Bento Gonçalves, 2012.

FONTOURA, F. B. B. da. Gestão de custos. São Paulo: Atlas, 2013.

FRY T.D; STEELE, D.C; SALADIN, B.A. The role of management accounting in the development of a manufacturing strategy. IJOPM, vol.15, No12, 1995, p. 21-31.

HOOZÉE, S.; BRUGGEMAN, W. Identifying operational improvements during the design process of a time-driven ABC system: The role of collective worker participation and leadership style. Management Accounting Research, v.21, n.3, p.185-199, 2010.

KAPLAN, R. S. COOPER, R. Custo e desempenho. 2. Ed. São Paulo. Editora Futura, 2000.

KAPLAN, R. S.; ANDERSON, S. R. Time driven activity-based costing. Harward Bussiness Review, Volume 82, No. 11 de Novembro de 2004.

Custeio baseado em atividades e tempo. Time driven activity-based costing - o caminho prático e eficaz para aumentar a lucratividade. Rio de Janeiro: Elsevier, 2007. 
KOONTZ, H.; O’DONNELL, C. Fundamentos da Administração. 2. ed. São Paulo: Livraria Pioneira, 1981.

NAMAZI, M. Performance focused ABC: a third generation of activity-based costing system. Cost Management, 23 (5): 34-46. 2009

PADOVEZE, C. L.; TAKAKURA JR.; Franco K. Custos e preços de serviços. São Paulo: Ed. Atlas, 2013.

RODRIGUES, E. Z.; SILVA, W. A. C.; ARAÚJO, E., A. T. Custeio Baseado em Atividade e Tempo - TDABC: estudo de caso em uma instituição de ensino superior particular.

SANTANA, A. F. B. AFONSO, P. FAGUNDES, J. A. Time-Driven Activity-Based Costing (TDABC): um perfil dos artigos publicados no Congresso Brasileiro de Custos. Anais: XX Congresso Brasileiro de Custos, Uberlândia, 2013.

SANTANA, G. A. S.; COLAUTO, R. D.; CARRIERI, A. P. Institucionalização de instrumentos de custeio para o controle gerencial: o caso de uma organização do setor elétrico. Anais: XVII Congresso Brasileiro de Custos, Belo Horizonte, 2010.

SHANK, J. K.; GOVINDARAJAN, V. A revolução dos custos: como reinventar e redefinir sua estratégia de custos para vencer em mercados crescentemente competitivos. $2^{\mathrm{a}}$. ed. Rio de Janeiro: Campus, 1997.

SCHULTZ, A. C. et al. Produção científica na área de custos no setor de serviços no período de 2000 a 2004. Anais: X Congresso Brasileiro de Custos. Espírito Santo, 2004.

SOUZA, A. A.de; AVELAR, E. A.; BOINA, T. M.; GUERRA, M. Análise da aplicabilidade do time-driven ABC: estudos de casos múltiplos. In: CONGRESSO BRASILEIRO DE CUSTOS, 17, Belo Horizonte. Anais... novembro, 2010.p.1-15.

SOUZA, A. A.; AVElAR, E. A.; BOINA, T. M.; LARA, C. O. Análise dos estudos empíricos realizados sobre o time-driven ABC entre os anos de 2004 e 2008. Anais: $9^{\circ}$ Congresso USP de Controladoria e Contabilidade. São Paulo: FEA/USP, 2009.

TSE, M.S.C.; GONG, M.Z. (2009): "Recognition of idle resources in time-driven activitybased costing and resource consumption accounting models". Journal of Applied Management Accounting Research, 7 (2): 41-54.

UFC. Universidade Federal do Ceará. Disponível em: www.ufc.br. Acesso em 14 jan.2016

WERNKE, R. LEMBECK, M., MENDES, E. Z. ABC versus TDABC: estudo de caso aplicado no setor de manutenção de veículos de uma transportadora de passageiros. Anais: XVI Congresso Brasileiro de Custos. Fortaleza, 2009.

WICKRAMASINGHE, D.; ALAWATTAGE, C. Management accounting change: Approaches and perspectives. New York: Routledge. 2007 